\title{
Article \\ Enriched Multivalued Contractions with Applications to Differential Inclusions and Dynamic Programming
}

\author{
Mujahid Abbas ${ }^{1,+} \mathbb{D}$, Rizwan Anjum ${ }^{2,+}$ (D) and Vasile Berinde ${ }^{3,4, *,+}$ \\ 1 Department of Mathematics, Government College University, Katchery Road, Lahore 54000, Pakistan; \\ abbas.mujahid@gcu.edu.pk \\ 2 Abdus Salam School of Mathematical Sciences, Government College University, Lahore 54600, Pakistan; \\ rizwananjum1723@sms.edu.pk \\ 3 Department of Mathematics and Computer Science, North University Center at Baia Mare, \\ Technical University of Cluj-Napoca, Victoriei 76, 430122 Baia Mare, Romania \\ 4 Academy of Romanian Scientists, Ilfov Str. No. 3, 50044 Bucharest, Romania \\ * Correspondence: vasile.berinde@mi.utcluj.ro \\ + These authors contributed equally to this work.
}

check for updates

Citation: Abbas, M.; Anjum, R; Berinde, V. Enriched Multivalued Contractions with Applications to Differential Inclusions and Dynamic Programming. Symmetry 2021, 13, 1350. https://doi.org/10.3390/sym 13081350

Academic Editor: Sun Young Cho

Received: 17 June 2021

Accepted: 22 July 2021

Published: 26 July 2021

Publisher's Note: MDPI stays neutral with regard to jurisdictional claims in published maps and institutional affiliations.

Copyright: (c) 2021 by the authors. Licensee MDPI, Basel, Switzerland. This article is an open access article distributed under the terms and conditions of the Creative Commons Attribution (CC BY) license (https:/ / creativecommons.org/licenses/by/ $4.0 /)$.

\begin{abstract}
The purpose of this paper is to introduce the class of enriched multivalued contraction mappings. Both single-valued and multivalued enriched contractions are defined by means of symmetric inequalities. Our main result extends and generalizes the recent result of Berinde and Păcurar (Approximating fixed points of enriched contractions in Banach spaces, Journal of Fixed Point Theory and Applications, 22 (2), 1-10, 2020). We also study a data dependence problem of the fixed point set and Ulam-Hyers stability of the fixed point problem for enriched multivalued contraction mappings. Applications of the results obtained to the problem of the existence of a solution of differential inclusions and dynamic programming are presented.
\end{abstract}

Keywords: Banach space; enriched multi-valued contraction; fixed point; iterative method; data dependence; Ulam-Hyers stability; differential inclusion; dynamic programming

\section{Introduction and Preliminaries}

In 1922, Banach [1] demonstrated a significant conclusion for fixed point theory on the metric spaces, known as the Banach contraction principle. Because of its applications in various fields of nonlinear analysis and applied mathematical analysis, this principle has been generalized and extended in different ways.

One of the interesting and famous generalizations was proved by Nadler [2] by applying the concept of the Pompeiu-Hausdorff metric defined on a family of closed and bounded subsets of a complete metric space (see [3]). He established the concept of multi-valued contraction mappings.

Throughout this paper, the standard notations and terminologies in nonlinear analysis (see $[4,5])$ are used. For the convenience of the reader, we recall some of them.

Let $(X, d)$ be a metric space. Let $C B(X)$ and $(C(X))$ be the class of all nonempty closed and bounded (compact) subsets of $X$, respectively.

The symmetric functional $H: C B(X) \times C B(X) \rightarrow[0, \infty)$ defined by

$$
H(A, B)=\max \{D(A, B), D(B, A)\},
$$

where $D(A, B)=\sup _{x \in A} \inf _{y \in B} d(x, y)$, for all $A, B \in C B(X)$, is a metric called the Pompeiu-Hausdorff metric.

Nadler had proved the following fixed point theorem for multivalued mappings satisfying a symmetric contraction condition. 
Theorem 1 ([2]). Let $(X, d)$ be a complete metric space and $T: X \rightarrow C B(X)$ be a multi-valued contraction mapping satisfying

$$
H(T x, T y) \leq k d(x, y),
$$

for all $x, y \in X$, where $k$ is a constant such that $k \in(0,1)$. Then, $T$ has a fixed point; that is, there exist a point $z \in X$ such that $z \in T z$.

Later, several interesting fixed point theorem for multi-valued mappings were obtained (see [4-13] and especially the monographs of Rus [14-16]).

Let $T: X \rightarrow C B(X)$ be a given mapping. For any fixed $x_{0}$ in $X$, a sequence $\left\{x_{n}\right\}$ in $X$ such that $x_{n+1} \in T x_{n}$ is called a $T$-orbital sequence around $x_{0}$. The set $O\left(T, x_{0}\right)$ denotes the collection of all such sequences. Further, an element $x \in X$ is called a fixed point of $T$, if $x \in T(x)$. The set of all fixed points of a multi-valued $T$ is denoted by Fix $(T)$, that is, Fix $(T)=\{x \in X: x \in T(x)\}$. A multi-valued mapping $T: X \rightarrow C B(X)$ is called a Lipschitzian mapping if, for all $x, y \in X$, there exists some $L \geq 0$ such that $H(T x, T y) \leq L d(x, y)$ holds. If we take $L=1$ in the previous inequality, then the Lipschitzian mapping $T$ is called nonexpansive.

The following data dependence problem is well known.

Let $T_{1}, T_{2}: X \rightarrow P(X)$ be two multi-valued mappings such that Fix $\left(T_{1}\right)$ and Fix $\left(T_{2}\right)$ are nonempty and there exists $\delta>0$ with the property that $H\left(T_{1} x, T_{2} x\right) \leq \delta$, for all $x \in X$.

Under these conditions, estimate $H\left(\operatorname{Fix}\left(T_{1}, \operatorname{Fix}\left(T_{2}\right)\right)\right.$, where $P(X)$ is the power set of $X$. Several partial answers to this problem are given in [17-19].

The stability problems of functional equations originated from a question of Ulam [20] concerning the stability of group homomorphisms. Hyers [21] gave a partial answer to the question of Ulam [20] for Banach spaces.

Let $(X, d)$ be a metric space and $T: X \rightarrow 2^{X}$ a multi-valued mapping. Consider the fixed point problem

$$
x \in T x .
$$

Let $\epsilon>0$. An element $w^{*} \in X$ is called an $\epsilon$-solution of the fixed point problem (2) if there exists $y^{*} \in X$ such that

$$
D\left(w^{*}, T y^{*}\right) \leq \epsilon .
$$

The fixed point problem (2) is called Ulam-Hyers stable if there exists a finite constant $c>0$ such that for each $\epsilon>0$ and for each $\epsilon$-solution $x^{*} \in X$ of the fixed point problem (2) there exist solutions $w^{*} \in X$ of problem (2) such that

$$
d\left(x^{*}, w^{*}\right) \leq c \epsilon .
$$

Following the authors of [22,23], a single-valued mapping $T: X \rightarrow X$ is called an enriched contraction or $(b, \theta)$-enriched contraction [22] if there exist two constants, $b \in[0, \infty)$ and $\theta \in[0, b+1)$, such that, for all $x, y \in X$,

$$
\|b(x-y)+T x-T y\| \leq \theta\|x-y\|,
$$

and enriched nonexpansive or $b$-enriched nonexpansive [23] if

$$
\|b(x-y)+T x-T y\| \leq(b+1)\|x-y\|, \quad \forall x, y \in X,
$$

respectively.

Note that the above two contractive conditions are both symmetric. We state Theorem 2.4 of [22] for convenience and in view of extending to the case of multi-valued mappings.

Theorem 2 ([22]). Let $(X,\|\cdot\|)$ be a Banach space and $T: X \rightarrow X$ be $a(b, \theta)$-enriched contraction. Then,

1. Thas a unique fixed point $p$. 
2. There exist $\lambda \in[0,1)$ such that the iterative method $\left\{x_{n}\right\}_{n=0}^{\infty}$, given by

$$
x_{n+1}=(1-\lambda) x_{n}+\lambda T x_{n}, \quad n \geq 0,
$$

converges to $p$ for any $x_{0} \in X$.

3. The following estimate holds

$$
\left\|x_{n+i-1}-p\right\| \leq \frac{c^{i}}{1-c}\left\|x_{n}-x_{n-1}\right\|, \quad n=0,1, \ldots ; i=1,2, \ldots
$$

where $c=\frac{\theta}{b+1}$.

As shown in [22], a lot of well-known contractive conditions from the literature imply the $(b, \theta)$-enriched contraction. Therefore, Theorem 2 includes as particular cases the Banach contraction principle and several important fixed point theorems in the literature.

The purpose of this paper is to extend the concept of enriched contraction and enriched nonexpansive from the case of single-valued mappings to multi-valued mappings, which not only includes the class of multi-valued contraction mappings but also the class of some Lipschitzian mappings as a subclass. We study a data dependence problem of the fixed point sets and Ulam-Hyers stability of the fixed point problem for enriched multi-valued mappings. We present applications of our results in establishing the existence of a solution of a differential inclusion problem, dynamic programming; introduce a algorithm in real Hilbert space; prove a strong convergence theorem for approximating a common solution of fixed point inclusion for enriched multi-valued nonexpansive mapping and equilibrium problem of a bifunction.

\section{Main Results}

We introduce now the notions of enriched multi-valued contraction and enriched multi-valued nonexpansive mapping by means of the following two symmetric contractive type inequalities.

Definition 1. Let $(X,\|\cdot\|)$ be a linear normed space. A multi-valued mapping $T: X \rightarrow C B(X)$ is called:

(i) Enriched multi-valued contraction if there exists $b \in[0, \infty)$ and $\theta \in[0, b+1)$ such that

$$
H(b x+T x, b y+T y) \leq \theta\|x-y\|, \quad \forall x, y \in X
$$

(ii) Enriched multi-valued nonexpansive if for all $x, y \in X$, we have

$$
H(b x+T x, b y+T y) \leq(b+1)\|x-y\| .
$$

To indicate the constant involved in (6) and (7), we also call $T a(b, \theta)$-enriched multi-valued contraction and b-enriched multi-valued nonexpansive, respectively.

Example 1. Any multi-valued contraction (1) mapping $T$ with contraction constant $L$ is $(0, L)$ enriched multi-valued contraction, i.e., T satisfies (6) with $b=0$ and $\theta=L \in[0,1)$.

Every multi-valued nonexpansive mapping $T$ is 0-enriched multi-valued nonexpansive.

Example 2. Let $(Y, \mu)$ be a finite measure space. The classical Lebesgue space $X=L^{2}(Y, \mu)$ is defined as the collection of all Borel measurable functions $f: Y \rightarrow \mathbb{R}$ such that $\int_{Y}|f(y)|^{2} d \mu(y)<\infty$. We know that the space $X$ equipped with the norm $\|f\|_{X}=\left(\int_{Y}|f|^{2} d \mu\right)^{\frac{1}{2}}$ is a Banach space. Define the mapping $T: L^{2}(Y, \mu) \rightarrow C B\left(L^{2}(Y, \mu)\right)$ by

$$
T f=\{-f, g-f\},
$$


where $g(y)=1, \forall y \in Y$. Clearly, $g \in L^{2}(Y, \mu)$ as $\mu(Y)<\infty$.

Note that $T$ is an $(1,1)$-enriched multi-valued contraction mapping but not a contraction mapping in the sense of Nadler [2].

Indeed, if we take $f_{1}, f_{2} \in L^{2}(Y, \mu)$, such that $f_{1}(y)=3$ and $f_{2}(y)=6, \forall y \in Y$, then clearly,

$$
d\left(-f_{1}, T f_{2}\right)=\inf \left\{\left\|-f_{1}+f_{2}\right\|,\left\|-f_{1}-g+f_{2}\right\|\right\}
$$

Note that

$$
\left\|-f_{1}+f_{2}\right\|^{2}=\int_{Y}\left|-f_{1}+f_{2}\right|^{2} d \mu=\int_{Y}(-3+6)^{2} d \mu=3^{2} \mu(Y)
$$

and

$$
\left\|-f_{1}-g+f_{2}\right\|^{2}=\int_{Y}\left|-f_{1}-g+f_{2}\right|^{2} d \mu=\int_{Y}(-3-1+6)^{2} d \mu=2^{2} \mu(Y)
$$

Thus,

$$
d\left(-f_{1}, T f_{2}\right)=2[\mu(Y)]^{\frac{1}{2}}
$$

Similarly, we have

$$
d\left(g-f_{1}, T f_{2}\right)=\inf \left\{\left\|g-f_{1}+f_{2}\right\|,\left\|-f_{1}+f_{2}\right\|\right\}
$$

Note that,

$$
\begin{gathered}
\left\|g-f_{1}+f_{2}\right\|^{2}=\int_{Y}\left|g-f_{1}+f_{2}\right|^{2} d \mu=\int_{Y}(1-3+6)^{2} d \mu=4^{2} \mu(Y) \\
\left\|g-f_{1}+f_{2}\right\|=4[\mu(Y)]^{\frac{1}{2}} .
\end{gathered}
$$

Thus,

$$
d\left(g-f_{1}, T f_{2}\right)=3[\mu(Y)]^{\frac{1}{2}} .
$$

Therefore,

$$
D\left(T f_{1}, T f_{2}\right)=\sup \left\{d\left(-f_{1}, T f_{2}\right), d\left(g-f_{1}, T f_{2}\right)\right\}=3[\mu(Y)]^{\frac{1}{2}}
$$

Similarly,

$$
D\left(T f_{2}, T f_{1}\right)=3[\mu(Y)]^{\frac{1}{2}}
$$

and hence

$$
H\left(T f_{1}, T f_{2}\right)=3[\mu(Y)]^{\frac{1}{2}}
$$

Note that

$$
\left\|f_{1}-f_{2}\right\|=\left(\int_{Y}\left|f_{1}-f_{2}\right|^{2} d \mu\right)^{\frac{1}{2}}=\left(\int_{Y}(3-6)^{2} d \mu\right)^{\frac{1}{2}}=3[\mu(Y)]^{\frac{1}{2}}=H\left(T f_{1}, T f_{2}\right) .
$$

On the other hand,

$$
f+T f=\{\mathbf{0}, g\},
$$

where $\mathbf{0}$ is the zero measurable function on $Y$. Clearly, we have

$$
d(\mathbf{0}, h+T h)=\inf \{\|\mathbf{0}\|,\|\mathbf{0}-g\|\}=0
$$

and

$$
d(g, h+T h)=0
$$


which gives that $D(f+T f, h+T h)=0$. Similarly, $D(h+T h, f+T f)=0$. Thus,

$$
\begin{aligned}
H(f+T f, h+T h) & =\max \{D(f+T f, h+T h), D(h+T h, f+T f)\} \\
& =0 \leq d(f, h), \forall f, h \in L^{2}(Y, \mu) .
\end{aligned}
$$

Hence, $T$ is $(1,1)$-enriched multi-valued contraction. In addition,

$$
\operatorname{Fix}(T)=\left\{\mathbf{0}, \frac{g}{2}\right\}
$$

Remark 1. Let $M$ be a convex subset of a linear space $X$ and $T: M \rightarrow C B(M)$. Then, for any $\lambda \in(0,1)$, consider the mapping $T_{\lambda}: M \rightarrow C B(M)$ given by

$$
\begin{aligned}
T_{\lambda}(x) & =(1-\lambda) x+\lambda T x \\
& =\{(1-\lambda) x+\lambda s: s \in T x\} .
\end{aligned}
$$

In other words, for each $x$ in $M, T_{\lambda}(x)$ is the translation of the set $\lambda T x$ by the vector $(1-\lambda) x$. Clearly,

$$
\operatorname{Fix}\left(T_{\lambda}\right)=\operatorname{Fix}(T) .
$$

Indeed, if $p \in T p$, then $p=(1-\lambda) p+\lambda p \in T_{\lambda} p$. On the other hand, if $p \in T_{\lambda} p$, then for some $s \in T p$, we have $p=(1-\lambda) p+\lambda$ s which further implies that $s=p$.

We need the following Lemma of Nadler [2] (see also [7] ).

Lemma 1 ([7]). Let $(X, d)$ be a metric space, $A, B \subset X$ and $q>1$. Then, for each $a \in A$, there exists $b \in B$ such that

$$
d(a, b) \leq q H(A, B)
$$

We now prove the following fixed point theorem for a $(b, \theta)$-enriched multi-valued contraction in normed space. In the sequel, the letters $\mathbb{R}$ and $\mathbb{N}$ denote the set of all real numbers and the set of all natural numbers, respectively.

Theorem 3. Let $(X,\|\|$.$) be a normed space, T: X \rightarrow C B(X) a(b, \theta)$-enriched multi-valued contraction. Then,

1. $\operatorname{Fix}(T)=\left\{x^{*}\right\}$;

2. There exist a $T_{\lambda}$-orbital sequence $\left\{x_{n}\right\}_{n=0}^{\infty}$ around $x_{0}$ that converges to the fixed point $x^{*}$ of $T$, for which the following estimates hold:

$$
\begin{aligned}
& d\left(x_{n}, x^{*}\right) \leq \frac{h^{n}}{1-h} d\left(x_{0}, x_{1}\right), \quad n=0,1,2, \ldots \\
& d\left(x_{n}, x^{*}\right) \leq \frac{h}{1-h} d\left(x_{n-1}, x_{n}\right), \quad n=1,2, \ldots
\end{aligned}
$$

provided that for some $x_{0}$ in $X$, the $T_{\lambda}$-orbital subset $O\left(T_{\lambda}, x_{0}\right)$ is a complete subset of $X$ where $h=\frac{q \theta}{b+1}$ for certain $q>1$ and $\lambda=\frac{1}{b+1}$.

Proof. We divide the proof into the following two cases.

Case 1 . Suppose that $b>0$. Take $\lambda=\frac{1}{b+1}$. Clearly, $0<\lambda<1$. In this case, we have

$$
H\left(\left(\frac{1}{\lambda}-1\right) x+T x,\left(\frac{1}{\lambda}-1\right) y+T y\right) \leq \theta d(x, y)
$$

and hence

$$
H((1-\lambda) x+\lambda T x,(1-\lambda) y+\lambda T y) \leq \theta \lambda d(x, y) .
$$


Equivalently, for each $x, y \in X$, we have

$$
H\left(T_{\lambda} x, T_{\lambda} y\right) \leq c d(x, y),
$$

where $c=\theta \lambda$, and $T_{\lambda}$ is defined as in (14). As $\theta \in(0, b+1)$, so $c \in(0,1)$ and hence the mapping $T_{\lambda}$ is a contraction in the sense of Nadler [2].

Let $q>1, x_{0} \in X$ and $x_{1} \in T_{\lambda} x_{0}$. If $H\left(T_{\lambda} x_{0}, T_{\lambda} x_{1}\right)=0$, then $T_{\lambda} x_{0}=T_{\lambda} x_{1}$ implies that $x_{1} \in T_{\lambda} x_{1}$ and hence $\operatorname{Fix}\left(T_{\lambda}\right) \neq \varnothing$.

Suppose that $H\left(T_{\lambda} x_{0}, T_{\lambda} x_{1}\right) \neq 0$. Then, by Lemma 1 , there exists $x_{2} \in T_{\lambda} x_{1}$ such that

$$
d\left(x_{1}, x_{2}\right) \leq q H\left(T_{\lambda} x_{0}, T_{\lambda} x_{1}\right) \leq q c d\left(x_{0}, x_{1}\right) .
$$

We may take $q>1$ such that $h=q c<1$ and hence

$$
d\left(x_{1}, x_{2}\right)<h d\left(x_{0}, x_{1}\right) .
$$

If $H\left(T_{\lambda} x_{1}, T_{\lambda} x_{2}\right)=0$. Then, $T_{\lambda} x_{1}=T_{\lambda} x_{2}$ gives that $x_{2} \in T_{\lambda} x_{2}$. Suppose that $H\left(T_{\lambda} x_{1}, T_{\lambda} x_{2}\right) \neq 0$. Following the arguments similar to those given above, there exists $x_{3} \in T_{\lambda} x_{2}$ such that

$$
d\left(x_{2}, x_{3}\right) \leq h d\left(x_{1}, x_{2}\right)
$$

Continuing this way, we can obtain a sequence $\left\{x_{n}\right\}_{n=0}^{\infty}$ in $X$ such that $x_{n+1} \in T_{\lambda} x_{n}$ and it satisfies

$$
d\left(x_{n}, x_{n+1}\right) \leq h d\left(x_{n-1}, x_{n}\right), n=0,1,2, \ldots, .
$$

By (19), we inductively obtain that

$$
d\left(x_{n}, x_{n+1}\right) \leq h^{n} d\left(x_{0}, x_{1}\right),
$$

and

$$
d\left(x_{n+k}, x_{n+k+1}\right) \leq h^{k+1} d\left(x_{n-1}, x_{n}\right), \quad k \in \mathbb{N}, n \geq 1 .
$$

By (20), and triangular inequality, we have

$$
d\left(x_{n}, x_{n+p}\right) \leq \frac{h^{n}\left(1-h^{p}\right)}{1-h} d\left(x_{0}, x_{1}\right),
$$

for all $n, p \in \mathbb{N}$. Hence,

$$
d\left(x_{n}, x_{n+p}\right) \leq \frac{h^{n}}{1-h} d\left(x_{0}, x_{1}\right)
$$

which, in view of $0<h<1$ gives that $\left\{x_{n}\right\}_{n=0}^{\infty}$ is a Cauchy sequence in the subspace $O\left(T_{\lambda}, x_{0}\right)$ of $X$. Next, we assume that there exists an element $x^{*}$ in $O\left(T_{\lambda}, x_{0}\right)$ such that $\lim _{n \rightarrow \infty} x_{n}=x^{*}$. Note that

$$
\begin{aligned}
D\left(x^{*}, T_{\lambda} x^{*}\right) & \leq d\left(x^{*}, x_{n+1}\right)+D\left(x_{n+1}, T_{\lambda} x^{*}\right) \\
& \leq d\left(x^{*}, x_{n+1}\right)+H\left(T_{\lambda} x_{n}, T_{\lambda} x^{*}\right) \\
& \leq d\left(x^{*}, x_{n+1}\right)+c d\left(x^{*}, x_{n}\right) .
\end{aligned}
$$

On taking the limit as $n \rightarrow \infty$, we get that $D\left(x^{*}, T_{\lambda} x^{*}\right)=0$. Since $T_{\lambda} x^{*}$ is closed, $x^{*} \in T_{\lambda} x^{*}$.

Case 2. $b=0$. In this case, the enriched multi-valued contraction (6) becomes,

$$
H(T x, T y) \leq \theta d(x, y) \quad \forall x, y \in X,
$$

where $\theta \in(0,1)$. That is, $T$ is a multi-valued contraction mapping in the sense of Nadler and hence $\operatorname{Fix}(T) \neq \varnothing$, by Nadler's fixed point theorem. 
To obtain (16), we let $p \rightarrow \infty$ in (22). By (21), we get similarly to (3.10)

$$
d\left(x_{n}, x_{n+p}\right) \leq \frac{h\left(1-h^{p}\right)}{1-h} d\left(x_{n-1}, x_{n}\right), \quad p \in \mathbb{N}, n \geq 1
$$

and letting $p \rightarrow \infty$ in (25) we obtain (17).

Example 3. Let $X=\mathbb{R} \backslash\left\{\frac{1}{5}, \frac{-1}{5}, \frac{4}{5}\right\}$ be endowed with the usual norm and let $T: X \rightarrow C B(X)$ be defined by $T x=\{-x, 1-x\}$, for all $x \in X$. Then, clearly $T$ is a $(1,1)$-enriched multi-valued contraction. As $\lambda=\frac{1}{b+1}$, this gives $\lambda=\frac{1}{2}$. Let $x_{0}=0$ be fixed in $X$. Then, we have

$$
T_{\frac{1}{2}}\left(x_{0}\right)=\frac{1}{2} x_{0}+\frac{1}{2} T x_{0}=\frac{1}{2}(0)+\frac{1}{2}\{0,1\}=\left\{0, \frac{1}{2}\right\} \text {. }
$$

Pick $x_{1}=0$ in $T_{\frac{1}{2}}\left(x_{0}\right)$. Similarly, in this way, we get $T_{\frac{1}{2}}\left(x_{1}\right)=\left\{0, \frac{1}{2}\right\}$. Pick $x_{2}=0 \in T_{\frac{1}{2}} x_{1}$. Continuing in this same way, we obtain $x_{n+1} \in T_{\frac{1}{2}}\left(x_{n}\right)$, where $x_{n+1}=(0,0,0, \ldots)$, we obtain a Cauchy sequence $\left\{x_{n}\right\}_{n \in \mathbb{N}}$ which converges to 0 and 0 is the fixed point of $T$.

We now prove the following fixed point theorem for a $(b, \theta)$-enriched multi-valued contraction in a Banach space.

Corollary 1. Let $(X,\|\|$.$) be a Banach space and T: X \rightarrow C B(X)$ a $(b, \theta)$-enriched multi-valued contraction. Then, $\operatorname{Fix}(T) \neq \varnothing$.

Proof. Following arguments similar to those in the proof of Theorem 3 , the result follows.

As a corollary of our result, we can obtain Nadler's fixed point theorem for multivalued mappings, in the setting of a Banach space.

Corollary 2 ([2]). Let $(X,\|\|$.$) be a Banach space and T: X \rightarrow C B(X)$ a multi-valued contraction, that is,

$$
H(T x, T y) \leq \theta d(x, y), \quad \forall x, y \in X
$$

Then, $\operatorname{Fix}(T) \neq \varnothing$. of [22].

If in Corollary 1 for $T$ we take a single valued mapping, then we obtain Theorem 2.4

Corollary 3. Let $(X,\|\cdot\|)$ be a Banach space and $T: X \rightarrow X a(b, \theta)$-enriched contraction, that is,

$$
\|b(x-y)+T x-T y\| \leq \theta\|x-y\|, \quad \forall x, y \in X .
$$

Then, T has a unique fixed point.

We now prove the following fixed point theorem for $b$-enriched multi-valued nonexpansive mappings in a uniformly convex Banach space.

Theorem 4. Let $X$ be a uniformly convex Banach space and $D$ a closed convex bounded nonempty subset of $X$. Let $T: D \rightarrow C(D)$ be a b enriched multi-valued nonexpansive mapping. Then, $T$ has a fixed point, i.e., there exists $x \in D$ with $x \in T x$.

Proof. We divide the proof into the following two cases. 
Case 1. Suppose that $b>0$. Clearly, $0<\lambda=\frac{1}{b+1}<1$. In this case, an $b$-enriched multi-valued nonexpansive condition (7) reduces to the following form

$$
H\left(T_{\lambda} x, T_{\lambda} y\right) \leq d(x, y)
$$

Clearly, $T_{\lambda}$ satisfies all the conditions of Theorem 1 of [24]. Hence Fix $(T) \neq \varnothing$.

Case 2. Suppose that $b=0$. In this case, we have $\lambda=1$.

Then, $\operatorname{Fix}(T) \neq \varnothing$ by Theorem 1 of [24].

As a corollary of our result, we can obtain Theorem 1 of [24] for multi-valued mappings.

Corollary 4 ([24]). Let X be a uniformly convex Banach space and let $D$ be a closed convex bounded nonempty subset of $X$. Let $T: D \rightarrow C(D)$ be a 0 -enriched multi-valued nonexpansive mapping. Then, $T$ has a fixed point, i.e., there exists $x \in D$ with $x \in T x$.

\section{Approximation Methods for Enriched Multi-Valued Nonexpansive Nonself Mappings and Equilibrium Problems}

Let $H$ be a real Hilbert space with inner product $\langle\cdot, \cdot\rangle$. Let $D$ be a nonempty and convex subset of $H$ and let $F: D \times D \rightarrow \mathbb{R}$ be a bifunction. The equilibrium problem for $F$ is to find $u \in D$ such that

$$
F(u, y) \geq 0, \quad \forall y \in D .
$$

The solutions set of (26) is denoted by $E P(F)$. The equilibrium problem (26) includes as special cases numerous problems in physics, optimization, and economics. Some methods have been continuously constructed for solving the equilibrium problem (see, for example, Refs. $[25,26]$ and references therein). Let $X$ be a Banach space and $D$ a subset of $X$. A multivalued mapping $T: D \rightarrow C B(X)$ is said to satisfy the condition (A), if $\|x-p\|=D(x, T p)$ for all $x \in X$ and $p \in \operatorname{Fix}(T)$.

When $\left\{x_{n}\right\}$ is a sequence in $H, x_{n} \rightarrow x$ implies that $\left\{x_{n}\right\}$ converges weakly to $x$ and $x_{n} \rightarrow x$ means the strong convergence. In a real Hilbert space $H$, we have

$$
\|\lambda x+(1-\lambda) y\|^{2}=\lambda\|x\|^{2}+(1-\lambda)\|x\|^{2}-\lambda(1-\lambda)\|x-y\|^{2},
$$

for all $x, y \in H$ and $\lambda \in[0,1]$. Let $D$ be a closed and convex subset of $H$. For every point $x \in H$, there exists a unique nearest point in $D$, denoted by $P_{D} x$, such that

$$
\left\|x-P_{D} x\right\| \leq\|x-y\|, \quad \forall y \in D .
$$

$P_{D}$ is called the metric projection of $H$ onto $D$.

For solving the equilibrium problem for a bifunction $F: D \times D \rightarrow \mathbb{R}$, let us assume that $F$ satisfies the following conditions:

(A1) $F(x, x)=0$, for all $x \in D$.

(A2) $F$ is monotone, i.e., $F(x, y)+F(y, x) \leq 0, \forall x, y \in D$.

(A3) For each $x, y, z \in D$,

$$
\lim _{t \downarrow 0} F(t z+(1-t) x, y) \leq F(x, y) .
$$

(A4) For each $x \in D, y \mapsto F(x, y)$ is convex and lower semicontinuous.

The following is used for the proof if our main results in the sequel.

Lemma 2 ([27]). Let $\left\{s_{n}\right\}$ be a sequence of nonnegative real numbers, $\left\{\alpha_{n}\right\}$ be a sequence in $[0,1]$ with $\sum_{n=1}^{\infty} \alpha_{n}=\infty,\left\{\beta_{n}\right\}$ be the sequence of nonnegative real numbers with $\sum_{n=1}^{\infty} \beta_{n}<\infty$, and $\left\{\gamma_{n}\right\}$ be the sequence of real numbers with $\limsup _{n \rightarrow \infty} \gamma_{n} \leq 0$. Suppose that

$$
s_{n+1}=\left(1-\alpha_{n}\right) s_{n}+\alpha_{n} \gamma_{n}+\beta_{n},
$$

for all $n \in \mathbb{N}$. Then, $\lim _{n \rightarrow \infty} s_{n}=0$. 
Lemma 3 ([27]). Let $D$ be a closed and convex subset of a real Hilbert space $H$ and $P_{D}$ be the metric projection from $H$ onto $D$. Given $x \in H$ and $z \in D, z=P_{D} x$ if and only if

$$
\langle x-z, y-z\rangle \leq 0, \forall y \in D
$$

Lemma 4 ([27]). For $r>0, x \in H$, define the mapping $T^{r}: H \rightarrow D$ as follows:

$$
T^{r}(x)=\left\{z \in D: F(z, y)+\frac{1}{r}\langle y-z, z-x\rangle \geq 0, \forall y \in D\right\} .
$$

Then, the following hold:

1. $T^{r}$ is single-value.

2. $T^{r}$ is firmly nonexpansive, i.e., for any $x, y \in H$,

$$
\left\|T^{r} x-T^{r} y\right\|^{2} \leq\left\langle T^{r} x-T^{r} y, x-y\right\rangle .
$$

3. $\operatorname{Fix}\left(T^{r}\right)=E P(F)$.

4. $E P(F)$ is closed and convex.

Lemma 5. Let $D$ be a closed and convex subset of Hilbert space $H$. Let $T: D \rightarrow C(D)$ be a b-enriched multi-valued nonexpansive mapping with Fix $(T) \neq \varnothing$ and $T p=\{p\}$ for each $p \in \operatorname{Fix}(T)$. Then, Fix $(T)$ is a closed and convex subset of $D$.

Proof. We divide the proof into the following two cases.

Case 1. Suppose that $b>0$. Clearly, $0<\lambda=\frac{1}{b+1}<1$. In this case, a $b$-enriched multi-valued nonexpansive condition (7) reduces to the following form

$$
H\left(T_{\lambda} x, T_{\lambda} y\right) \leq d(x, y)
$$

First, we show that Fix $\left(T_{\lambda}\right)$ is closed. Let $\left\{x_{n}\right\}$ be sequence in Fix $\left(T_{\lambda}\right)$ such that $x_{n} \rightarrow x$ as $n \rightarrow \infty$. We have

$$
\begin{aligned}
D\left(x, T_{\lambda} x\right) & \leq d\left(x, x_{n}\right)+D\left(x_{n}, T_{\lambda} x\right) \\
& \leq d\left(x, x_{n}\right)+H\left(T_{\lambda} x_{n}, T_{\lambda} x\right) \\
& =2 d\left(x, x_{n}\right) .
\end{aligned}
$$

It follows that $D\left(x, T_{\lambda} x\right)=0$, so $x \in \operatorname{Fix}\left(T_{\lambda}\right)$. Next, we show that $\operatorname{Fix}\left(T_{\lambda}\right)$ is convex. Let $p=t p_{1}+(1-t) p_{2}$ where $p_{1}, p_{2} \in \operatorname{Fix}\left(T_{\lambda}\right)$ and $t \in(0,1)$. Let $z \in T_{\lambda} p$, we have

$$
\begin{aligned}
\|p-z\|^{2} & =\left\|t\left(z-p_{1}\right)+(1-t)\left(z-p_{2}\right)\right\|^{2} \\
& =t\left\|z-p_{1}\right\|^{2}+(1-t)\left\|z-p_{2}\right\|^{2}-t(1-t)\left\|p_{1}-p_{2}\right\|^{2} \\
& =t D\left(z, T_{\lambda} p_{1}\right)^{2}+(1-t) D\left(z, T_{\lambda} p_{2}\right)^{2}-t(1-t)\left\|p_{1}-p_{2}\right\|^{2} \\
& \leq t H\left(T_{\lambda} p, T_{\lambda} p_{1}\right)^{2}+(1-t) H\left(T_{\lambda} p, T_{\lambda} p_{2}\right)^{2}-t(1-t)\left\|p_{1}-p_{2}\right\|^{2} \\
& \leq t\left\|p-p_{1}\right\|^{2}+(1-t)\left\|p-p_{2}\right\|^{2}-t(1-t)\left\|p_{1}-p_{2}\right\|^{2} \\
& =t(1-t)^{2}\left\|p_{2}-p_{1}\right\|^{2}+(1-t) t^{2}\left\|p_{1}-p_{2}\right\|^{2}-t(1-t)\left\|p_{1}-p_{2}\right\|^{2} \\
& =0 .
\end{aligned}
$$

Hence, $p=z$. Therefore, $p \in \operatorname{Fix}(T)$.

Case 2. Suppose that $b=0$. In this case, we have $\lambda=1$. Then, Fix $(T)$ is a closed and convex subset of $D$ by Lemma 2.7 of [27].

Using the above results, we study convergence of the following iteration (27). Let $D$ be a nonempty, closed, and convex subset of a Hilbert space $H$. Let $T: D \rightarrow C(H)$ be a multi-valued nonself mapping, $f: H \rightarrow H$ a contraction, and $F: D \times D \rightarrow \mathbb{R}$ a bifunction. 
Let $\left\{\alpha_{n}\right\}$ be a sequence in $[0,1]$ and $\left\{r_{n}\right\}$ a sequence in $(0, \infty)$. For a given $x_{0} \in H$, we compute

$$
u_{0} \in D \text { such that } F\left(u_{0}, y\right)+\frac{1}{r_{0}}\left\langle y-u_{0}, u_{0}-x_{0}\right\rangle \geq 0, \forall y \in D,
$$

then we let $z_{0} \in T_{\lambda} u_{0}$ for some $\lambda \in(0,1)$ and define $x_{1} \in D$ by

$$
x_{1}=\alpha_{0} f\left(x_{0}\right)+\left(1-\alpha_{0}\right) z_{0} .
$$

We next compute

$$
u_{1} \in D \text { such that } F\left(u_{1}, y\right)+\frac{1}{r_{1}}\left\langle y-u_{1}, u_{1}-x_{1}\right\rangle \geq 0, \forall y \in D .
$$

From Nadler's Theorem (see [2]), it follows that there exists $z_{1} \in T_{\lambda} u_{1}$ such that $\left\|z_{1}-z_{0}\right\| \leq H\left(T_{\lambda} u_{1}, T_{\lambda} u_{0}\right)$. Inductively, we construct the sequence $\left\{x_{n}\right\}$ as follows:

$$
\left\{\begin{array}{l}
u_{n} \in D: F\left(u_{n}, y\right)+\frac{1}{r_{n}}\left\langle y-u_{n}, u_{n}-x_{n}\right\rangle \geq 0, \forall y \in D, \\
x_{n+1}=\alpha_{n} f\left(x_{n}\right)+\left(1-\alpha_{n}\right) z_{n}, n \geq 0 .
\end{array}\right.
$$

Here, $z_{n} \in T_{\lambda} u_{n}$ is such that $\left\|z_{n+1}-z_{n}\right\| \leq H\left(T_{\lambda} u_{n+1}, T_{\lambda} u_{n}\right)$ for $n \geq 1$.

Now, we prove a strong convergence theorem of the iteration (27) to find the common element of the solutions set of an equilibrium problem and the fixed points set of a multivalued nonself mapping.

Theorem 5. Let $D$ be a nonempty, closed, and convex subset of a Hilbert space $H$. Let $F$ be a bifunction from $D \times D$ to $\mathbb{R}$ satisfying (A1)-(A4) and T a b-enriched multi-valued nonexpansive mapping of $D$ into $C(H)$ such that Fix $(T) \cap E P(F) \neq \varnothing$. Let $f$ be a contraction of $H$ into itself. Let $\left\{\alpha_{n}\right\} \subset[0,1]$ and $\left\{r_{n}\right\} \subset(0, \infty)$ be sequence satisfied the following conditions:

(i) $\lim _{n \rightarrow \infty} \alpha_{n}=0, \sum_{n=0}^{\infty} \alpha_{n}=\infty$ and $\sum_{n=0}^{\infty}\left|\alpha_{n+1}-\alpha_{n}\right|<\infty$.

(ii) $\liminf _{n \rightarrow \infty} r_{n}>0$ and $\sum_{n=0}^{\infty}\left|r_{n+1}-r_{n}\right|<\infty$.

If $T_{\lambda}$ satisfies Condition $(A)$, then the sequence $\left\{x_{n}\right\}$ and $\left\{u_{n}\right\}$ generated by (27) converges to $z \in \operatorname{Fix}(T) \cap E P(F)$, where $z=P_{F(T) \cap E P(F)} f(z)$ and $\lambda=\frac{1}{b+1}$.

Proof. Take $\lambda=\frac{1}{b+1}$; then, the $b$-enriched multi-valued nonexpansive condition (7) reduces to the following form

$$
H\left(T_{\lambda} x, T_{\lambda} y\right) \leq d(x, y)
$$

Using Lemmas 4 and 5, we define $Q=P_{F(T) \cap E P(F)}$. Since $f$ is a contraction, there exists a constant $\alpha \in[0,1)$ such that

$$
\|Q f(x)-Q f(y)\| \leq\|f(x)-f(y)\| \leq \alpha\|x-y\|
$$

for all $x, y \in H$. Hence, $Q f$ is a contraction of $H$ into itself. Thus, there exists a unique element $z \in H$ such that $z=Q f(z)$. We next divide the proof into five steps.

Step 1. Show that $\left\{x_{n}\right\}$ is bounded.

Let $p \in \operatorname{Fix}(T) \cap E P(F)$. Then, $u_{n}=T^{r_{n}} x_{n}$, and we have

$$
\left\|u_{n}-p\right\|=\left\|T^{r_{n}} x_{n}-T^{r_{n}} p\right\| \leq\left\|x_{n}-p\right\|,
$$


for all $n \in \mathbb{N}$. It follows from (28) that

$$
\begin{aligned}
\left\|x_{n+1}-p\right\| & \leq \alpha_{n}\left\|f x_{n}-p\right\|+\left(1-\alpha_{n}\right)\left\|z_{n}-p\right\| \\
& \left.\leq \alpha_{n}\left(\left\|f x_{n}-p\right\|\right)+\|f p-p\|\right)+\left(1-\alpha_{n}\right) D\left(z_{n}, T_{\lambda} p\right) \\
& \left.\leq \alpha_{n}\left(\alpha\left\|x_{n}-p\right\|\right)+\|f p-p\|\right)+\left(1-\alpha_{n}\right) H\left(T_{\lambda} z_{n}, T_{\lambda} p\right) \\
& \left.\leq \alpha_{n}\left(\alpha\left\|x_{n}-p\right\|\right)+\|f p-p\|\right)+\left(1-\alpha_{n}\right)\left\|u_{n}-p\right\| \\
& \leq\left(1-\alpha_{n}(1-\alpha)\right)\left\|x_{n}-p\right\|+\alpha_{n}(1-\alpha) \frac{1}{1-\alpha}\|f p-p\| \\
& \leq \max \left\{\left\|x_{n}-p\right\|, \frac{1}{1-\alpha}\|f p-p\|\right\} .
\end{aligned}
$$

By induction, we have

$$
\left\|x_{n}-p\right\| \leq \max \left\{\left\|x_{0}-p\right\|, \frac{1}{1-\alpha}\|f p-p\|\right\}, \forall n \geq 0 .
$$

Hence, $\left\{x_{n}\right\}$ is bounded, and so are the sequences $\left\{u_{n}\right\},\left\{z_{n}\right\}$ and $\left\{f x_{n}\right\}$.

Step 2. Show that $\left\|x_{n+1}-x_{n}\right\| \rightarrow 0$ as $n \rightarrow \infty$.

From the definition of $\left\{x_{n}\right\}$, there exist $z_{n+1} \in T_{\lambda} u_{n+1}$ and $z_{n} \in T_{\lambda} u_{n}$ such that $\left\|z_{n+1}-z_{n}\right\| \leq H\left(T_{\lambda} u_{n+1}, T_{\lambda} u_{n}\right)$. Put $K=\sup _{n \geq 0}\left\{\left\|f x_{n}\right\|+\left\|z_{n}\right\|\right\}$. Then, we have

$$
\begin{aligned}
& \left\|x_{n+2}-x_{n+1}\right\| \\
& =\| \alpha_{n+1} f x_{n+1}-\alpha_{n+1} f x_{n}+\alpha_{n+1} f x_{n}-\alpha_{n} f x_{n} \\
& \quad+\left(1-\alpha_{n+1}\right) z_{n+1}-\left(1-\alpha_{n+1}\right) z_{n}+\left(1-\alpha_{n+1}\right) z_{n}-\left(1-\alpha_{n}\right) z_{n} \| \\
& \leq \alpha_{n+1} \alpha\left\|x_{n+1}-x_{n}\right\|+\left|\alpha_{n+1}-\alpha_{n}\right|\left\|f x_{n}\right\|+\left(1-\alpha_{n+1}\right)\left\|z_{n+1}-z_{n}\right\| \\
& \quad+\mid \alpha_{n+1}-\alpha_{n}\left\|z_{n}\right\| \\
& \leq \alpha_{n+1} \alpha\left\|x_{n+1}-x_{n}\right\|+\left|\alpha_{n+1}-\alpha_{n}\right|\left\|f x_{n}\right\| \\
& \quad+\left(1-\alpha_{n+1}\right) H\left(T_{\lambda} u_{n+1}, T_{\lambda} u_{n}\right)+\mid \alpha_{n+1}-\alpha_{n}\left\|z_{n}\right\| \\
& \leq \alpha_{n+1} \alpha\left\|x_{n+1}-x_{n}\right\|+2 K\left|\alpha_{n+1}-\alpha_{n}\right| \\
& \quad+\left(1-\alpha_{n+1}\right)\left\|u_{n+1}-u_{n}\right\| .
\end{aligned}
$$

On the other hand, from $u_{n}=T^{r_{n}} x_{n}$ and $u_{n+1}=T^{r_{n+1}} x_{n+1}$, we have

$$
F\left(u_{n}, y\right)+\frac{1}{r_{n}}\left\langle y-u_{n}, u_{n}-x_{n}\right\rangle \geq 0,
$$

for all $y \in D$ and

$$
F\left(u_{n+1}, y\right)+\frac{1}{r_{n+1}}\left\langle y-u_{n+1}, u_{n+1}-x_{n+1}\right\rangle \geq 0,
$$

for all $y \in D$. Setting $y=u_{n+1}$ in (30) and $y=u_{n}$ in (31), we have

$$
F\left(u_{n}, u_{n+1}\right)+\frac{1}{r_{n}}\left\langle u_{n+1}-u_{n}, u_{n}-x_{n}\right\rangle \geq 0,
$$

and

$$
F\left(u_{n+1}, u_{n}\right)+\frac{1}{r_{n+1}}\left\langle u_{n}-u_{n+1}, u_{n+1}-x_{n+1}\right\rangle \geq 0 .
$$

It follows from (A2) that

$$
\left\langle u_{n+1}-u_{n}, \frac{u_{n}-x_{n}}{r_{n}}-\frac{u_{n+1}-x_{n+1}}{r_{n+1}}\right\rangle \geq 0
$$


and hence

$$
\left\langle u_{n+1}-u_{n}, u_{n}-u_{n+1}+u_{n+1}-x_{n}-\frac{r_{n}}{r_{n+1}}\left(u_{n+1}-x_{n+1}\right)\right\rangle \geq 0 .
$$

Without loss of generality, let us assume that there exists a real number $\alpha$ such that $r_{n}>a>0$ for all $n \geq 0$. Then, we have

$$
\begin{aligned}
\left\|u_{n+1}-u_{n}\right\|^{2} \leq & \left\langle u_{n+1}-u_{n}, x_{n+1}-x_{n}+\left(1-\frac{r_{n}}{r_{n+1}}\right)\left(u_{n+1}-x_{n+1}\right)\right\rangle \\
& \leq\left\|u_{n+1}-u_{n}\right\|\left\{\left\|x_{n+1}-x_{n}\right\|+\left|\left(1-\frac{r_{n}}{r_{n+1}}\right)\right|\left\|u_{n+1}-x_{n+1}\right\|\right\}
\end{aligned}
$$

and hence

$$
\begin{gathered}
\left\|u_{n+1}-u_{n}\right\| \leq\left\|x_{n+1}-x_{n}\right\|+\frac{1}{r_{n+1}}\left|r_{n+1}-r_{n}\left\|\mid u_{n+1}-x_{n+1}\right\|\right. \\
\leq\left\|x_{n+1}-x_{n}\right\|+\frac{1}{a}\left|r_{n+1}-r_{n}\right| M
\end{gathered}
$$

where $M=\sup \left\{\left\|u_{n}-x_{n}\right\|: n \geq 0\right\}$. Combining (29) and (32), we obtain

$$
\begin{aligned}
\left\|x_{n+2}-x_{n+1}\right\| \leq \alpha_{n+1} \alpha\left\|x_{n+1}-x_{n}\right\|+2 K\left|\alpha_{n+1}-\alpha_{n}\right| & \\
& +\left(1-\alpha_{n+1}\right)\left(\left\|x_{n+1}-x_{n}\right\|+\frac{1}{a}\left|r_{n+1}-r_{n}\right| M\right) \\
= & \left(1-\alpha_{n+1}+\alpha_{n+1} \alpha\right)\left\|x_{n+1}-x_{n}\right\|+2 K\left|\alpha_{n+1}-\alpha_{n}\right| \\
& \quad+\left(1-\alpha_{n+1}\right) \frac{1}{a}\left|r_{n+1}-r_{n}\right| M \\
\leq & \left(1-\alpha_{n+1}(1-\alpha)\right)|| x_{n+1}-x_{n} \|+2 K\left|\alpha_{n+1}-\alpha_{n}\right| \\
& \quad+\frac{M}{a}\left|r_{n+1}-r_{n}\right| .
\end{aligned}
$$

By Conditions (i) and (ii), we have $\left\|x_{n+1}-x_{n}\right\| \rightarrow 0$ as $n \rightarrow \infty$ using Lemma 2.

Step 3. Show that $\lim _{n \rightarrow \infty}\left\|x_{n}-z_{n}\right\|=\lim _{n \rightarrow \infty}\left\|u_{n}-z_{n}\right\|=0$.

Using (32) and (ii), we have

$$
\lim _{n \rightarrow \infty}\left\|u_{n+1}-u_{n}\right\|=0 .
$$

Since $x_{n+1}=\alpha_{n} f x_{n}+\left(1-\alpha_{n}\right) z_{n}$,

$$
\left\|x_{n+1}-z_{n}\right\|=\alpha_{n}\left\|f x_{n}-z_{n}\right\| .
$$

Since $\alpha_{n} \rightarrow 0$ as $n \rightarrow \infty$ and, by Step 1 , the sequence $\left\{f x_{n}-z_{n}\right\}$ is bounded, we see $\left\|x_{n+1}-z_{n}\right\| \rightarrow 0$ as $n \rightarrow \infty$. This implies that

$$
\left\|x_{n}-z_{n}\right\| \leq\left\|x_{n}-x_{n+1}\right\|+\left\|x_{n+1}-z_{n}\right\| \rightarrow 0
$$

as $n \rightarrow \infty$. For $p \in \operatorname{Fix}(T) \cap E P(F)$, we have

$$
\begin{aligned}
\left\|u_{n}-p\right\|^{2} & =\left\|T^{r_{n}} x_{n}-T^{r_{n}} p\right\|^{2} \\
& \leq\left\langle T^{r_{n}} x_{n}-T^{r_{n}} p, x_{n}-p\right\rangle \\
& =\left\langle u_{n}-p, x_{n}-p\right\rangle \\
& =\frac{1}{2}\left(\left\|u_{n}-p\right\|^{2}+\left\|x_{n}-p\right\|^{2}-\left\|x_{n}-u_{n}\right\|^{2}\right),
\end{aligned}
$$


which yields

$$
\left\|u_{n}-p\right\|^{2} \leq\left\|x_{n}-p\right\|^{2}-\left\|x_{n}-u_{n}\right\|^{2} .
$$

Therefore, from the convexity of $\|\cdot\|^{2}$, we have

$$
\begin{aligned}
\left\|x_{n+1}-p\right\|^{2}= & \left\|\alpha_{n} f x_{n}-\left(1-\alpha_{n}\right) z_{n}-p\right\|^{2} \\
& \leq \alpha_{n}\left\|f x_{n}-p\right\|^{2}+\left(1-\alpha_{n}\right)\left\|z_{n}-p\right\|^{2} \\
& =\alpha_{n}\left\|f x_{n}-p\right\|^{2}+\left(1-\alpha_{n}\right) D\left(z_{n}, T_{\lambda} p\right)^{2} \\
& \leq \alpha_{n}\left\|f x_{n}-p\right\|^{2}+\left(1-\alpha_{n}\right) H\left(T_{\lambda} u_{n}, T_{\lambda} p\right)^{2} \\
& \leq \alpha_{n}\left\|f x_{n}-p\right\|^{2}+\left(1-\alpha_{n}\right)\left\|u_{n}-p\right\|^{2} \\
& \leq \alpha_{n}\left\|f x_{n}-p\right\|^{2}+\left(1-\alpha_{n}\right)\left(\left\|x_{n}-p\right\|^{2}-\left\|x_{n}-u_{n}\right\|^{2}\right) \\
& \leq \alpha_{n}\left\|f x_{n}-p\right\|^{2}+\left\|x_{n}-p\right\|^{2}-\left(1-\alpha_{n}\right)\left\|x_{n}-u_{n}\right\|^{2}
\end{aligned}
$$

and hence

$$
\begin{aligned}
\left(1-\alpha_{n}\right)\left\|x_{n}-u_{n}\right\|^{2} & \leq \alpha_{n}\left\|f x_{n}-p\right\|^{2}+\left\|x_{n}-p\right\|^{2}-\left\|x_{n+1}-p\right\|^{2} \\
& \leq \alpha_{n}\left\|f x_{n}-p\right\|^{2}+\left\|x_{n+1}-x_{n}\right\|\left(\left\|x_{n}-p\right\|+\left\|x_{n+1}-p\right\|\right)
\end{aligned}
$$

It follows from (i) and $\lim _{n \rightarrow \infty}\left\|x_{n+1}-x_{n}\right\|=0$ that

$$
\left\|x_{n}-u_{n}\right\| \rightarrow 0, \quad n \rightarrow \infty
$$

From (34) and (35), it follows that

$$
\left\|z_{n}-u_{n}\right\| \leq\left\|z_{n}-x_{n}\right\|+\left\|x_{n}-u_{n}\right\| \rightarrow 0 \quad n \rightarrow \infty .
$$

Step 4. Show that $\lim \sup _{n \rightarrow \infty}\left\langle f z-z, x_{n}-z\right\rangle \leq 0$, where $z=P_{F(T) \cap E P(F)} f(z)$. Firstly, we choose a subsequence $\left\{x_{n_{i}}\right\}$ of $\left\{x_{n}\right\}$ such that

$$
\lim _{i \rightarrow \infty}\left\langle f z-z, x_{n_{i}}-z\right\rangle=\limsup _{n \rightarrow \infty}\left\langle f z-z, x_{n}-z\right\rangle
$$

and $x_{n_{i}} \rightarrow q \in D$. From $\left\|x_{n}-u_{n}\right\| \rightarrow 0$, we obtain $u_{n_{i}} \rightarrow q$. Let us show $q \in E P(F)$. From $u_{n}=T^{r_{n}} x_{n}$, we have

$$
F\left(u_{n}, y\right)+\frac{1}{r_{n}}\left\langle y-u_{n}, u_{n}-x_{n}\right\rangle \geq 0, \forall y \in D .
$$

From (A2), we also have

$$
\frac{1}{r_{n}}\left\langle y-u_{n}, u_{n}-x_{n}\right\rangle \geq F\left(y, u_{n}\right)
$$

Since $\frac{u_{n_{i}}-x_{n_{i}}}{r_{n_{i}}} \rightarrow 0$ and $u_{n_{i}} \rightarrow q$, from (A4), we have

$$
0 \geq F(y, q),
$$

for all $y \in D$. For $t$ with $0<t \leq 1$ and $y \in D$, let $y_{t}=t y+(1-t) q$. Since $y \in D$ and $q \in D$, $y_{t} \in D$. Hence, $F\left(y_{t}, q\right) \leq 0$. Thus, from (A1) and (A4), we get

$$
0=F\left(y_{t}, y_{t}\right) \leq t F\left(y_{t}, y\right)+(1-t) F\left(y_{t}, q\right) \leq t F\left(y_{t}, y\right)
$$

and hence $0 \leq F\left(y_{t}, y\right)$. Thus, $0 \leq F(q, y)$ for all $y \in D$ by (A3) and hence $q \in E P(F)$. Since $\lim _{n \rightarrow \infty}\left\|z_{n}-u_{n}\right\|=0, u_{n_{i}} \rightarrow q$ and $I-T_{\lambda}$ is demiclosed at 0 , we obtain that $q \in \operatorname{Fix}\left(T_{\lambda}\right)=\operatorname{Fix}(T)$. Therefore, $q \in \operatorname{Fix}(T) \cap \operatorname{EP}(F)$. 
Since $z=P_{F(T) \cap E P(F)} f(z)$, by Lemma 3,

$$
\limsup _{n \rightarrow \infty}\left\langle f z-z, x_{n}-z\right\rangle=\lim _{i \rightarrow \infty}\left\langle f z-z, x_{n_{i}}-z\right\rangle=\langle f z-z, q-z\rangle \leq 0 .
$$

Step 5. Show that $x_{n} \rightarrow z$ as $n \rightarrow \infty$.

From the equality $x_{n+1}-z=\alpha_{n}\left(f x_{n}-z\right)+\left(1-\alpha_{n}\right)\left(z_{n}-z\right)$, we readily infer

$$
\left(1-\alpha_{n}\right)^{2}\left\|z_{n}-z\right\|^{2} \geq\left\|x_{n+1}-z\right\|^{2}-2 \alpha_{n}\left\langle f x_{n}-z, x_{n+1}-z\right\rangle .
$$

Hence, we obtain

$$
\begin{aligned}
\left\|x_{n+1}-z\right\|^{2} \leq & \left(1-\alpha_{n}\right)^{2}\left\|z_{n}-z\right\|^{2}+2 \alpha_{n}\left\langle f x_{n}-z, x_{n+1}-z\right\rangle \\
= & \left(1-\alpha_{n}\right)^{2} D\left(z_{n}, T_{\lambda} z\right)^{2}+2 \alpha_{n}\left\langle f x_{n}-z, x_{n+1}-z\right\rangle \\
\leq & \left(1-\alpha_{n}\right)^{2} H\left(T_{\lambda} u_{n}, T_{\lambda} z\right)^{2}+2 \alpha_{n}\left\langle f x_{n}-z, x_{n+1}-z\right\rangle \\
\leq & \left(1-\alpha_{n}\right)^{2}\left\|u_{n}-z\right\|^{2}+2 \alpha_{n}\left\langle f x_{n}-f z, x_{n+1}-z\right\rangle \\
& +2 \alpha_{n}\left\langle f z-z, x_{n+1}-z\right\rangle \\
\leq & \left(1-\alpha_{n}\right)^{2}\left\|x_{n}-z\right\|^{2}+2 \alpha_{n} \alpha\left\|x_{n}-z\right\|\left\|x_{n+1}-z\right\| \\
& +2 \alpha_{n}\left\langle f z-z, x_{n+1}-z\right\rangle \\
\leq & \left(1-\alpha_{n}\right)^{2}\left\|x_{n}-z\right\|^{2}+\alpha_{n} \alpha\left\{\left\|x_{n}-z\right\|^{2}+\left\|x_{n+1}-z\right\|^{2}\right\} \\
& +2 \alpha_{n}\left\langle f z-z, x_{n+1}-z\right\rangle .
\end{aligned}
$$

This implies that

$$
\begin{aligned}
\left\|x_{n+1}-z\right\|^{2} \leq & \frac{\left(1-\alpha_{n}\right)^{2}+\alpha_{n} \alpha}{1-\alpha_{n} \alpha}\left\|x_{n}-z\right\|^{2}+\frac{2 \alpha_{n}}{1-\alpha_{n} \alpha}\left\langle f z-z, x_{n+1}-z\right\rangle \\
= & \frac{1-2 \alpha_{n}+\alpha_{n} \alpha}{1-\alpha_{n} \alpha}\left\|x_{n}-z\right\|^{2}+\frac{\alpha_{n}^{2}}{1-\alpha_{n} \alpha}\left\|x_{n}-z\right\|^{2} \\
& +\frac{2 \alpha_{n}}{1-\alpha_{n} \alpha}\left\langle f z-z, x_{n+1}-z\right\rangle \\
= & \left(1-\frac{2 \alpha_{n}(1-\alpha)}{1-\alpha_{n} \alpha}\left\|x_{n}-z\right\|^{2}\right) \\
+ & \frac{2 \alpha_{n}(1-\alpha)}{1-\alpha_{n} \alpha}\left\{\frac{\alpha_{n}}{2(1-\alpha)}\left\|x_{n}-z\right\|^{2}+\frac{1}{1-\alpha}\left\langle f z-z, x_{n+1}-z\right\rangle\right\} .
\end{aligned}
$$

Put $\gamma_{n}=\frac{\alpha_{n}}{2(1-\alpha)}\left\|x_{n}-z\right\|^{2}+\frac{1}{1-\alpha}\left\langle f z-z, x_{n+1}-z\right\rangle$. It follows from (i) and (37) that $\limsup _{n \rightarrow \infty} \gamma_{n} \leq 0$. Thus, $\lim _{n \rightarrow \infty}\left\|x_{n}-z\right\|^{2}=0$ by Lemma 2 . This concludes that $\left\{x_{n}\right\}$ converges strongly to $z \in \operatorname{Fix}(T) \cap E P(F)$. We can easily check that $\left\{u_{n}\right\}$ also converges to $z$. We thus complete the proof.

Remark 2. If in Theorem 5 for $T$ we take a single valued mapping and $b=0$, then we obtain Theorem 3.2 of [26].

\section{Data Dependence and Uniform Convergence of Fixed Point Sets in Banach Spaces}

We now present the following data dependence result for $(b, \theta)$ enriched multi-valued mappings.

Theorem 6. Let $(X,\|\|$.$) be a Banach space and S, T: X \rightarrow C B(X)$ be multi-valued mappings. Assume that

1. $S$ is a $\left(b_{1}, \theta_{1}\right)$-enriched multi-valued contraction.

2. $T$ is a $\left(b_{2}, \theta_{2}\right)$-enriched multi-valued contraction.

3. There exists $\delta>0$ such that $H(S x, T x) \leq \delta, \forall x \in X$. 
Then, $\operatorname{Fix}(S), \operatorname{Fix}(T) \in C B(X)$.

Moreover,

$$
H(\operatorname{Fix}(S), \operatorname{Fix}(T)) \leq \frac{\delta}{1-\max \left\{c_{1}, c_{2}\right\}},
$$

where $c_{1}=\theta_{1}\left(\frac{1}{b_{1}}+1\right)$ and $c_{2}=\theta_{2}\left(\frac{1}{b_{2}}+1\right)$.

Proof. It follows from (1) that $\operatorname{Fix}\left(S_{\lambda}\right)=\operatorname{Fix}(S)$ and $\operatorname{Fix}\left(T_{\lambda}\right)=\operatorname{Fix}(T)$. As $S$ and $T$ are $\left(b_{1}, \theta_{1}\right)$ - and $\left(b_{2}, \theta_{2}\right)$-enriched multi-valued contractions, respectively, by Corollary 1 , $\operatorname{Fix}(S) \neq \varnothing$ and $\operatorname{Fix}(T) \neq \varnothing$.

Let $z_{n} \in \operatorname{Fix}\left(T_{\lambda}\right)$ be such that $z_{n} \rightarrow z$ as $n \rightarrow \infty$, that is, $\lim _{n \rightarrow \infty} d\left(z_{n}, z\right)=0$. Using (18), we have

$$
\begin{aligned}
d\left(z, T_{\lambda} z\right) & \leq d\left(z, z_{n}\right)+D\left(z_{n}, T_{\lambda} z\right) \\
& \leq d\left(z, z_{n}\right)+H\left(T_{\lambda} z_{n}, T_{\lambda} z\right) \\
& \leq d\left(z, z_{n}\right)+c_{2} d\left(z_{n}, z\right) .
\end{aligned}
$$

On taking limit as $n \rightarrow \infty$, we obtain $d\left(z, T_{\lambda} z\right)=0$. Hence, Fix $(T)$ is closed. Similarly, the set Fix $(S)$ is closed. To prove the remaining part of the theorem, let $q>1$. Then, for an arbitrary $x_{0} \in \operatorname{Fix}\left(S_{\lambda}\right)$, there exists $x_{1} \in T_{\lambda} x_{0}$ such that

$$
d\left(x_{0}, x_{1}\right) \leq q H\left(S_{\lambda} x_{0}, T_{\lambda} x_{0}\right)
$$

As $x_{1} \in T_{\lambda} x_{0}$, there exists $x_{2} \in T_{\lambda} x_{1}$ such that

$$
\begin{aligned}
d\left(x_{1}, x_{2}\right) & \leq q H\left(T_{\lambda} x_{1}, T_{\lambda} x_{2}\right) \\
& \leq q c_{2} d\left(x_{1}, x_{2}\right) \\
& =h d\left(x_{1}, x_{2}\right) .
\end{aligned}
$$

We take $q>1$ such that $h=q c_{2}<1$. Following arguments similar to those given in the proof of Theorem 1, we get

$$
d\left(x_{n}, x_{n+p}\right) \leq \frac{h^{n}}{1-h} d\left(x_{0}, x_{1}\right),
$$

for any $n, p \in \mathbb{N}$. On taking limit as $n \rightarrow \infty$, we obtain that $\left\{x_{n}\right\}$ is a Cauchy sequence in $X$. Since $X$ is a Banach space, we have $x_{n} \rightarrow x^{*}$, for some $x^{*}$ in $X$. In addition, $x^{*} \in T_{\lambda} x^{*}$. By (39), we obtain that

$$
d\left(x_{n}, x^{*}\right) \leq \frac{h^{n}}{1-h} d\left(x_{0}, x_{1}\right) .
$$

In particular, we get

$$
d\left(x_{0}, x^{*}\right) \leq \frac{1}{1-h} d\left(x_{0}, x_{1}\right) \leq \frac{\delta}{1-h^{\prime}},
$$

where $h=q c_{2}$. Similarly, for each $a_{0} \in \operatorname{Fix}\left(T_{\lambda}\right)$, there is an $a \in \operatorname{Fix}\left(S_{\lambda}\right)$ such that

$$
d\left(a_{0}, a\right) \leq \frac{1}{1-h} d\left(a_{0}, a_{1}\right) \leq \frac{\delta}{1-h^{\prime}},
$$

where $h^{\prime}=q c_{1}$. By (40) and (41), we obtain that

$$
H\left(\operatorname{Fix}\left(S_{\lambda}\right), \operatorname{Fix}\left(T_{\lambda}\right)\right) \leq \frac{\delta}{1-\max \left\{q c_{1}, q c_{2}\right\}}
$$


Hence,

$$
H(\operatorname{Fix}(S), \operatorname{Fix}(T)) \leq \frac{\delta}{1-\max \left\{q c_{1}, q c_{2}\right\}} .
$$

Letting $q \searrow 1$ in the previous inequality, we get the conclusion.

Theorem 7. Let $(X,\|\|$.$) be a Banach space and T_{n}: X \rightarrow C B(X)$ a sequence of $\left(b_{n}, \theta_{n}\right)$-enriched multi-valued mappings, for $n=0,1,2, \ldots$ If the sequence $\left\{T_{n}\right\}$ converges to $T_{0}$ uniformly on $X$, then

$$
\lim _{n \rightarrow \infty} H\left(\operatorname{Fix}\left(T_{n}\right), \operatorname{Fix}\left(T_{0}\right)\right)=0 .
$$

Proof. As $\left\{T_{n}\right\}$ converges to $T_{0}$ uniformly on $X$, for an arbitrary $\epsilon>0$, there exists $n_{0} \in \mathbb{N}$ such that

$$
\sup _{x \in X} H\left(\operatorname{Fix}\left(T_{n}(x)\right), \operatorname{Fix}\left(T_{0}(x)\right)\right)<\left(1-\max _{n \in \mathbb{N}}\left\{c_{0}, c_{n}\right\}\right) \epsilon, \quad \forall n \geq n_{0} .
$$

If we set $\delta=\left(1-\max _{n \in \mathbb{N}}\left\{c_{0}, c_{n}\right\}\right) \epsilon$, then $H\left(\operatorname{Fix}\left(T_{n}\right)(x), \operatorname{Fix}\left(T_{0}\right)(x)\right)<\delta$ for all $n \geq n_{0}$ and $x \in X$. Then, by Theorem 6 , we have

$$
H\left(F\left(T_{n}\right), F\left(T_{0}\right)\right) \leq \frac{\delta}{\left(1-\max _{n \in \mathbb{N}}\left\{c_{0}, c_{n}\right\}\right)} \leq \epsilon, \quad \forall n \geq n_{0} .
$$

Theorem 8. Let $(X,\|\|$.$) be a Banach space. Suppose that all the hypotheses of Corollary 1$ hold. Then, the fixed point problem (2) is Ulam-Hyers stable.

Proof. From Remark 1, it follows that the fixed point problem (2) is equivalent to the fixed point problem

$$
x \in T_{\lambda} x
$$

Let $y^{*}$ be an $\epsilon$-solution of (42). Hence, we see that

$$
D\left(y^{*}, T_{\lambda} y^{*}\right) \leq \epsilon
$$

Using (18) and 43, we get

$$
\begin{gathered}
d\left(x^{*}, y^{*}\right) \leq D\left(x^{*}, T_{\lambda} y^{*}\right)+D\left(y^{*}, T_{\lambda} y^{*}\right) \leq H\left(T_{\lambda} x^{*}, T_{\lambda} y^{*}\right)+\epsilon \\
\leq c d\left(x^{*}, y^{*}\right)+\epsilon=\frac{\epsilon}{1-c}=c^{\prime} \epsilon,
\end{gathered}
$$

where $c^{\prime}=\frac{1}{1-c}$. Since $0 \leq c<1$, this gives $c^{\prime}>0$.

\section{Application to Differential Inclusions}

In this section, as an application of the result proven in the above section, we prove the existence of solutions to the problem of differential inclusions. Before that, recall the following concept. Let $I$ be the interval in the real line $\mathbb{R}$. A function $f: I \rightarrow \mathbb{R}$ is absolutely continuous on $I$ if, for every positive number $\epsilon$, there is a positive number $\delta$ such that, whenever a finite sequence of pairwise disjoint sub-intervals $\left(a_{k}, b_{k}\right)$ of $I$ with $a_{k}<b_{k} \in I$ satisfies

$$
\begin{gathered}
\sum_{k}\left(b_{k}-a_{k}\right)<\delta, \\
\sum_{k}\left|f\left(b_{k}\right)-f\left(a_{k}\right)\right|<\epsilon .
\end{gathered}
$$


Let $\alpha>0$ and $K=[0, \alpha]$. The space of all real valued continuous (absolutely continuous) functions on $K$ equipped with supremum norm is denoted by $C(K)(A C(K))$.

We consider the following time dependent differential inclusion problem: find $x$ in $A C(K)$ such that

$$
x^{\prime}(t) \in G(t, x(t)) \text {, for almost every } t \in K,
$$

where $G: K \times \mathbb{R} \rightarrow 2^{\mathbb{R}}$ is a given multi-valued mapping satisfying certain conditions.

Next, we prove the existence of the solution to the differential inclusion problem (44). Denote by $S_{G}(x)$ the set of Lebesgue integrable selections of $G(\cdot, x(\cdot))$, i.e.,

$$
S_{G}(x)=\left\{g \in L^{1}(K, \mathbb{R}): g(t) \in G(t, x(t)) \text { for almost every } t \in K\right\} .
$$

Definition 2. A function $x \in A C(K)$ is said to be the solution of the problem (44), if there exists $g \in S_{G}(x)$ such that

$$
x^{\prime}(t)=g(t) \text { holds for almost every } t \text { in } K .
$$

Theorem 9. Suppose that the following conditions are satisfied:

1. $S_{G}(x) \neq \varnothing, \forall x \in C(K)$.

2. For every fixed $x \in C(K)$ and for any sequence $\left\{g_{n}\right\}$ in $S_{G}(x)$, there exists a subsequence $\left\{g_{n_{i}}\right\}$ of $\left\{g_{n}\right\}$ such that $\left\{g_{n_{i}}\right\}$ converges to a function $g \in L^{1}(K, \mathbb{R})$ as $i \rightarrow \infty$ for almost every $t \in K$ and

$$
\int_{0}^{t} g_{n_{i}}(s) d s \rightarrow \int_{0}^{t} g(s) d s, \text { as } i \rightarrow \infty .
$$

3. $G(t, s)$ is closed for all $(t, s) \in K \times \mathbb{R}$.

4. For each fixed $x \in C(K), G(\cdot, x(\cdot))$, is bounded on $\mathrm{K}$.

5. There exists $\phi \in L^{1}(K, \mathbb{R})$ with $\sup _{t \in K} \int_{0}^{t}|\phi(s)| d s \leq \frac{1}{2}$ and for all $t \in K, x, y \in C(K)$, we have

$$
0 \leq\left|g_{x}(t)-g_{y}(t)\right| \leq|\phi(t)||x(t)-y(t)|,
$$

where $g_{x} \in S_{G}(x), g_{y} \in S_{G}(y)$.

Then, problem (44) has a solution.

Proof. Let $X=C(K)$. Define the multi-valued mapping $T$ on $X$ by

$$
T x=\left\{f \in X: f(t)=\int_{0}^{t} g(s) d s, t \in K, g \in S_{G}(x)\right\} .
$$

As $S_{G}(x)$ is nonempty for each $x \in X$, the multi-valued mapping $T$ is well defined. If $x \in T x$, then $x(t)=\int_{0}^{t} g(s) d s$ gives that

$$
x^{\prime}(t)=g(t) \text { for almost every } t \in K .
$$

Thus, the differential inclusion problem (44) is equivalent to the following inclusion:

$$
x(t) \in[T x](t), t \in K .
$$

We now show that the multi-valued mapping $T$ satisfies all the conditions of Corollary 1.

Clearly, $T x$ is nonempty for each $x \in X$. First, we prove that $T x$ is a closed subset of

$X$. For this, let $x \in X$ be fixed and $\left\{f_{n}\right\}$ a sequence in $T x$ such that $f_{n} \rightarrow f \in X$ as $n \rightarrow \infty$. Then, there exists a sequence $\left\{g_{n}\right\}$ in $S_{G}(x)$ such that

$$
f_{n}(t)=\int_{0}^{t} g_{n}(s) d s, t \in K .
$$


By the given hypotheses, there exists a subsequence $\left\{g_{n_{i}}\right\}$ of $\left\{g_{n}\right\}$ such that $\left\{g_{n_{i}}\right\}$ converges to a function $g \in L^{1}(K, \mathbb{R})$ as $i \rightarrow \infty$ for almost every $t \in K$ and

$$
\int_{0}^{t} g_{n_{i}}(s) d s \rightarrow \int_{0}^{t} g_{n}(s) d s, \text { as } i \rightarrow \infty .
$$

As $G(t, x(t))$ is closed for all $t \in K, g(t) \in G(t, x(t))$, for almost every $t \in K$ and hence $g \in S_{G}(x)$. Note that

$$
f(t)=\lim _{n \rightarrow \infty} f_{n}(t)=\lim _{n \rightarrow \infty} \int_{0}^{t} g_{n}(s) d s=\int_{0}^{t} g_{n_{i}}(s) d s=\int_{0}^{t} g(s) d s, \quad i \rightarrow \infty .
$$

Thus, $f \in T x$. Moreover, for a fixed $x \in X, G(\cdot, x(\cdot))$ is bounded on $K$. In addition, there exists $M>0$ such that $|g(t)| \leq M$ for almost every $t \in K$ and every $g \in S_{G}(x)$. Indeed, $g(t) \in G(t, x(t))$, for almost every $t \in K$. Hence, for all $f \in T x$, we have

$$
\sup _{t \in K}|f(t)| \leq \sup _{t \in K} \int_{0}^{t}|g(s) d s| \leq M \alpha .
$$

Therefore, $T$ has bounded values in $X$. Thus, $T: X \rightarrow C B(X)$.

We now show that $T$ is an enriched multi-valued contraction. For this, let $b>0$ be fixed. Let us denote $A=b x+T x$ and $B=b y+T y$ for fixed $x$ and $y$ in $X$. We know that

$$
H(b x+T x, b y+T y)=\max \{D(b x+T x, b y+T y), D(b y+T y, b x+T x)\}
$$

where

$$
D(b x+T x, b y+T y)=\sup _{f_{x} \in A} \inf _{f_{y} \in B} d\left(f_{x}, f_{y}\right)=\sup _{f_{x} \in A} \inf _{f_{y} \in B} \sup _{t \in K}\left|f_{x}-f_{y}\right|
$$

By using the values of $f_{x}$ and $f_{y}$, we get

$$
D(b x+T x, b y+T y)=\sup _{f_{x} \in A} \inf _{f_{y} \in B} \sup _{t \in K}\left|\left(b x(t)+\int_{0}^{t} g_{x}(s) d s\right)-\left(b y(t)+\int_{0}^{t} g_{y}(s) d s\right)\right|
$$

for some $g_{x} \in S_{G}(x), g_{y} \in S_{G}(y)$.

We have

$$
\begin{aligned}
& \left|\left(b x(t)+\int_{0}^{t} g_{x}(s) d s\right)-\left(b y(t)+\int_{0}^{t} g_{y}(s) d s\right)\right| \\
& \leq|b x(t)-b y(t)|+\left|\int_{0}^{t}\left[g_{x}(s)-g_{y}(s)\right] d s\right| \\
& \leq b|x(t)-y(t)|+\int_{0}^{t}\left|g_{x}(s)-g_{y}(s)\right| d s \\
& \leq b d(x, y)+\int_{0}^{t}\left|g_{x}(s)-g_{y}(s)\right| d s .
\end{aligned}
$$

By using (45) in the above inequality, we obtain that

$$
\begin{aligned}
& \left|\left(b x(t)+\int_{0}^{t} g_{x}(s) d s\right)-\left(b y(t)+\int_{0}^{t} g_{y}(s) d s\right)\right| \\
& \leq b d(x, y)+\int_{0}^{t}|\phi(s) \| x(s)-y(s)| d s \\
& \leq b d(x, y)+d(x, y) \int_{0}^{t}|\phi(s)| d s .
\end{aligned}
$$


Hence,

$$
\left|\left(b x(t)+\int_{0}^{t} g_{x}(s) d s\right)-\left(b y(t)+\int_{0}^{t} g_{y}(s) d s\right)\right| \leq\left(b+\int_{0}^{t}|\phi(s)| d s\right) d(x, y)
$$

From (48) and (47), we have

$$
D(b x+T x, b y+T y) \leq \sup _{f_{x} \in A} \inf _{f_{y} \in B} \sup _{t \in K}\left(b+\int_{0}^{t}|\phi(s)| d s\right) d(x, y) .
$$

Hence,

$$
D(b x+T x, b y+T y) \leq\left(b+\sup _{t \in K} \int_{0}^{t}|\phi(s)| d s\right) d(x, y) .
$$

Similarly, we obtain that

$$
D(b y+T y, b x+T x) \leq\left(b+\sup _{t \in K} \int_{0}^{t}|\phi(s)| d s\right) d(x, y) .
$$

Using (49) and (50) in (46), we have

$$
H(b x+T x, b y+T y) \leq\left(b+\sup _{t \in K} \int_{0}^{t}|\phi(s)| d s\right) d(x, y) .
$$

Let $\theta=\sup _{t \in K} \int_{0}^{t}|\phi(s)| d s$. Since $\sup _{t \in K} \int_{0}^{t}|\phi(s)| d s \leq \frac{1}{2}$, we get

$$
\sup _{t \in K} \int_{0}^{t}|\phi(s)| d s+b<b+1
$$

and so (51) becomes

$$
H(b x+T x, b y+T y) \leq \theta d(x, y), \quad \forall x, y \in X .
$$

Thus, all the conditions of Corollary 1 are satisfied, and hence we deduce the existence of a solution of (44).

Example 4. Consider the problem

$$
x^{\prime}(t) \in G(t, x(t)) \text { for almost every } t \in K=[0,1],
$$

where $G(t, x)=\left\{0, \frac{x}{4}\right\}$

We check that all the conditions of Theorem 9 are satisfied. Indeed,

1. $S_{G}(x) \neq \varnothing, \forall x \in C(K)$, since $f(t)=\frac{x(t)}{4}, t \in[0,1]$ is a Lebesgue integrable selection of $G(\cdot, x(\cdot))$.

2. For $x \in C(K)$ fixed and for any sequence $\left\{g_{n}\right\}$ in $S_{G}(x)$, we have, for every $n \in \mathbb{N}$, that $g_{n}(t)=\frac{x(t)}{4}$ except possibly for $t$ at a set of measure zero, $\left\{g_{n}\right\}$ converges at almost every point $t \in K$ towards the function $g \in L^{1}(K, \mathbb{R})$ given by $g(t)=\frac{x(t)}{4}, t \in K$, as $n \rightarrow \infty$, and, for every $t \in K$, we have

$$
\int_{0}^{t} g_{n}(s) d s=\int_{0}^{t} g(s) d s, \quad \forall n \in \mathbb{N} .
$$

3. It is clear that $G(t, x)$ is closed for all $(t, x) \in K \times C(K)$.

4. For $x \in C(K)$ fixed, $G(\cdot, x(\cdot))$, is bounded on $K$.

5. If we take $\phi(t)=\frac{1}{4}, \forall t \in[0,1]$ then for every $x, y \in C(K)$ and for all $t \in K$, we have

$$
0 \leq\left|g_{x}(t)-g_{y}(t)\right|=|\phi(t)||y(t)-x(t)|,
$$


for all $g_{x} \in S_{G}(x), g_{y} \in S_{G}(y)$.

By Theorem 9, there exists a solution to the differential inclusion problem (52). Indeed, $x(t)=e^{\frac{t}{4}}$ is the solution of the differential inclusion (52).

\section{An Application to Dynamic Programming}

Dynamic Programming has attracted the attention of several researchers due to its broad applicability in various disciplines of physical and social sciences. The origin of the theory of dynamic programming lies in multi-stage decision processes. In such processes, certain functional equations emerge in a usual fashion.

This section deals with functional equations that occur in some kinds of continuous multi-stage decision-making processes. We define below the continuous multi-stage decision-making mechanism as follows.

Let $S \subset X$ be the state space and $D \subset Y$ the decision space, where $X$ and $Y$ are Banach spaces. We denote a state vector by $x$ and a decision vector by $y$. Let $\pi: S \times D \rightarrow S$, $g: S \times D \rightarrow \mathbb{R}$, and $G: S \times D \times \mathbb{R} \rightarrow \mathbb{R}$ be the given mappings, where $\mathbb{R}$ is the field of real numbers. The return function $f: S \rightarrow \mathbb{R}$ of the continuous decision process is defined by the functional equation.

$$
f(x)=\sup _{y \in D}\{g(x, y)+G(x, y, f(\pi(x, y))\}, \quad x \in S .
$$

For more results in this direction, we refer to the works in [28-30].

Let $B(S)$ be the space of bounded real-valued functions on $S$.

Theorem 10. Let the notation be as just above and suppose that the following conditions are satisfied:

1. G and $g$ are bounded.

2. $|G(x, y, h z)-G(x, y, k z)| \leq s d(h, k)$,

for all $h, k \in B(S)$ and $(x, y, h(z)) \in S \times D \times \mathbb{R}$, where $z \in S$ and $s \leq \frac{1}{2}$.

Then, functional Equation (53) possesses a unique bounded solution on $S$.

Proof. We know that $B(S)$ equipped with the norm $\|h\|=\sup _{x \in S}|h x|$ is a Banach space. Define the operator $T$ on $B(S)$ by $T h=\varphi$, where

$$
\varphi(x)=\sup _{y \in D}\{g(x, y)+G(x, y, h(\pi(x, y))\} .
$$

Since $G$ and $g$ are bounded, $\varphi \in B(S)$. Moreover, the problem of finding any bounded solution of functional Equation (53) is equivalent to finding a fixed point of $T$.

Let $h_{1}, h_{2} \in B(S)$ and $T h_{1}=\varphi_{1}, T h_{2}=\varphi_{2}$. Then, for $i=1,2$, we have

$$
\varphi_{i}(x)=\sup _{y \in D}\left\{g(x, y)+G\left(x, y, h_{i}(\pi(x, y))\right\} .\right.
$$

Let $b>0$ be fixed real number. Choose $x \in S, y_{1}, y_{2} \in Y$ and $\epsilon>0$ such that

$$
\begin{gathered}
b h_{1}(x)+T h_{1}(x)<b h_{1}(x)+g\left(x, y_{1}\right)+G\left(x, y, h_{1}\left(\pi\left(x, y_{1}\right)\right)+\epsilon,\right. \\
b h_{2}(x)+T h_{2}(x)<b h_{2}(x)+g\left(x, y_{2}\right)+G\left(x, y, h_{2}\left(\pi\left(x, y_{2}\right)\right)+\epsilon,\right. \\
b h_{1}(x)+T h_{1}(x) \geq b h_{1}(x)+g\left(x, y_{2}\right)+G\left(x, y, h_{1}\left(\pi\left(x, y_{2}\right)\right),\right. \\
b h_{2}(x)+T h_{2}(x) \geq b h_{2}(x)+g\left(x, y_{1}\right)+G\left(x, y, h_{2}\left(\pi\left(x, y_{1}\right)\right) .\right.
\end{gathered}
$$


From (54) and (57), we have

$$
\begin{aligned}
b\left(h_{1}(x)-h_{2}(x)\right)+T h_{1}(x) & +T h_{2}(x)<b\left(h_{1}(x)-h_{2}(x)\right)+G\left(x, y, h_{1}\left(\pi\left(x, y_{1}\right)\right)\right. \\
& -G\left(x, y, h_{2}\left(\pi\left(x, y_{1}\right)\right)+\epsilon\right. \\
& \leq b\left|\left(h_{1}(x)-h_{2}(x)\right)\right| \\
& +\mid G\left(x, y, h_{1}\left(\pi\left(x, y_{1}\right)\right)-G\left(x, y, h_{2}\left(\pi\left(x, y_{1}\right)\right) \mid+\epsilon\right.\right. \\
& \leq b d\left(h_{1}, h_{2}\right)+c d\left(h_{1}, h_{2}\right) .
\end{aligned}
$$

Hence,

$$
b\left(h_{1}(x)-h_{2}(x)\right)+T h_{1}(x)+T h_{2}(x) \leq \theta d\left(h_{1}, h_{2}\right)
$$

where $\theta=b+c$. Since $0<c \leq \frac{1}{2}, \theta \in[0, b+1)$.

Similarly, it follows from (55) and (56) that

$$
b\left(h_{2}(x)-h_{1}(x)\right)+T h_{2}(x)+T h_{1}(x) \leq \theta d\left(h_{1}, h_{2}\right) .
$$

Finally, by (58) and (59), we have

$$
\left\|b\left(h_{1}-h_{2}\right)+T h_{1}-T h_{2}\right\| \leq \theta\left\|h_{1}-h_{2}\right\| .
$$

Thus, all the conditions of Corollary 3 are satisfied, and hence the functional Equation (53) possesses a unique bounded solution.

\section{Conclusions}

1. We introduce the classes of enriched multi-valued contractions and enriched multivalued nonexpansive contractions that include multi-valued contractions as a particular case, as well as some multi-valued nonexpansive and Lipschitzian mappings. For other related results, we refer to the works in [31-42].

2. We present examples to show that the class of enriched multi-valued contractions strictly includes the multi-valued contractions in the sense that there exist mappings which are not multi-valued contractions and belong to the class of enriched multivalued contractions.

3. We show that every enriched multi-valued contraction has a fixed point (Theorem 3). In particular, by the fixed point results established in this paper, we obtain the Nadler's fixed point theorem (Corollary 2) in the setting of a Banach space.

4. We obtain Corollary 1, which extends the fixed point theorem (Theorem 2.4, [22]) from the class of enriched single-valued contraction to enriched multi-valued contractions.

5. We show that every enriched multi-valued nonexpansive contraction has a fixed point (Theorem 4), and we provide an algorithm to estimate the common solution of the equilibrium problem and the enriched multi-valued nonexpansive one (Theorem 5).

6. We also obtain Theorems 6 and 8 for a data dependence problem of the fixed point sets and Ulam-Hyers stability of the fixed point problem for enriched multi-valued mappings, respectively.

7. As an application of our results (Corollaries 1 and 3), the existence of the solution to the problem of differential inclusions (Theorem 9) and the application to dynamic programming (Theorem 10) are presented.

Author Contributions: Conceptualization, M.A.; Supervision \& editing V.B.; Writing-review \& editing, R.A. All authors have read and agreed to the published version of the manuscript.

Funding: The first author was supported by the Higher Education Commission of Pakistan (project No. 9340). The third author acknowledges the constant support offered by the Department of Mathematics, Faculty of Sciences, North University Centre at Baia Mare, Technical University of Cluj-Napoca. 
Acknowledgments: Authors are thankful to the reviewers for their useful comments and constructive remarks that helped to improve the presentation of the paper.

Conflicts of Interest: The authors declare no conflict of interest.

\section{References}

1. Banach, S. Sur les opérations dans les ensembles abstraits et leurs applications aux équations intégrales. Fund. Math. 1922, 3, 133-181. [CrossRef]

2. Nadler, S.B., Jr. Multi-valued contraction mappings. Pac. J. Math. 1969, 30, 475-488. [CrossRef]

3. Berinde V.; Păcurar, M. The role of the Pompeiu-Hausdorff metric in fixed point theory. Creat. Math. Inform. 2013, $22,35-42$.

4. Assad, N.A. Fixed point theorems for set valued transformations on compact set. Boll. Un. Mat. Ital. 1973, 4, 1-7.

5. Berinde M.; Berinde V. On a general class of multi-valued weakly Picard mappings. J. Math. Anal. Appl. 2007, 326, 772-782. [CrossRef]

6. Assad, N.A.; Kirk, W.A. Fixed point theorems for set-valued mappings of contractive type. Pac. J. Math. 1972, 43, 553-562. [CrossRef]

7. Ciric, L.B. Fixed Point Theory. Contraction Mapping Principle; FME Press: Beograd, Serbia, 2003.

8. Ciric L.B.; Ume, J.S. Common fixed point theorems for multi-valued non-self mappings. Publ. Math. Debr. 2002, 60, 359-371.

9. Ciric, L.B.; Ume, J.S. On the convergence of the Ishikawa iterates to a common fixed point of multi-valued mappings. Demonstr. Math. 2003, 36, 951-956.

10. Itoh, S. Multi-valued generalized contractions and fixed point theorems. Comment. Math. Univ. Carolin. 1977, 18, 247-258.

11. Kaneko, H. A general principle for fixed points of contractive multi-valued mappings. Math. Japon. 1986, 31, 407-411.

12. Moţ G.; Petruşel, A. Fixed point theory for a new type of contractive multivalued operators. Nonlinear Anal. 2009, 70, 3371-3377. [CrossRef]

13. Rus, I.A.A.; Petruşel, A.; Petruşel, G. Fixed Point Theory; Cluj University Press: Cluj-Napoca, Romania, 2008.

14. Rus, I.A. Principles and Applications of the Fixed Point Theory; Editura Dacia: Cluj-Napoca, Romania, 1979. (In Romanian)

15. Rus, I.A. Basic problems of the metric fixed point theory revisited (II). Stud. Univ. Babeş-Bolyai Math. 1991, 36, 81-99.

16. Rus, I.A. Generalized Contractions and Applications; Cluj University Press: Cluj-Napoca, Romania, 2001.

17. Lim, T.C. On fixed point stability for set-valued contractive mappings with applications to generalized differential equations. J. Math. Anal. Appl. 1985, 110, 436-441. [CrossRef]

18. Markin, J.T. Continuous dependence of fixed point sets. Proc. Amer. Math. Soc. 1973, 38, 545-547. [CrossRef]

19. Rus I.A.; Mureşan, S. Data dependence of the fixed points set of weakly Picard operators. Stud. Univ. Babeş-Bolyai Math. 1998, 43, 79-83.

20. Ulam, S.M. A Collection of the Mathematical Problems; Interscience Publ.: New York, NY, USA, 1960.

21. Hyers, D.H. On the stability of the linear functional equation. Proc. Natl. Acad. Sci. USA 1941, 27, 222-224. [CrossRef] [PubMed]

22. Berinde V.; Păcurar, M. Approximating fixed points of enriched contractions in Banach spaces. J. Fixed Point Theory Appl. 2020, 22, 1-10. [CrossRef]

23. Berinde, V. Approximating fixed points of enriched nonexpansive mappings by Krasnoselskij iteration in Hilbert spaces. Carpathian J. Math. 2019, 35, 293-304. [CrossRef]

24. Lim, T.C. A fixed point theorem for multivalued nonexpansive mappings in a uniformly convex Banach space. Bull. Amer. Math. Soc. 1974, 80, 1123-1126. [CrossRef]

25. Blum E.; Oettli, W. From optimization and variational inequalities to equilibrium problems. Math. Student 1994, 63,123-145.

26. Takahashi, S.; Takahashi, W. Viscosity approximation methods for equilibrium problems and fixed point problems in Hilbert spaces. J. Math. Anal. Appl. 2007, 331, 506-515. [CrossRef]

27. Cholamjiak W.; Suantai, S. A hybrid method for a countable family of multivalued maps, equilibrium problems, and variational inequality problems. Discret. Dyn. Nat. Soc. 2010, 349158. [CrossRef]

28. Bellman R.; Lee, E.S. Functional equations in dynamic programming. Aequationes Math. 1978, 17, 1-18. [CrossRef]

29. Baskaran R.; Subrahmanyam, P.V. A note on the solution of a class of functional equations. Appl. Anal. 1986, 22, 235-241. [CrossRef]

30. Bhakta P.C.; Mitra, S. Some existence theorems for functional equations arising in dynamic programming. J. Math. Anal. Appl. 1984, 98, 348-362. [CrossRef]

31. Berinde, V. Weak and strong convergence theorems for the Krasnoselskij iterative algorithm in the class of enriched strictly pseudocontractive operators. An. Univ. Vest Timiş. Ser. Mat. Inform. 2018, 56, 13-27. [CrossRef]

32. Berinde, V. Approximating fixed points of enriched nonexpansive mappings in Banach spaces by using a retraction-displacement condition. Carpathian J. Math. 2020, 36, 27-34. [CrossRef]

33. Berinde, V.; Păcurar, M. Kannan's fixed point approximation for solving split feasibility and variational inequality problems. $J$. Comput. Appl. Math. 2021, 386, 113217. [CrossRef]

34. Berinde, V.; Păcurar, M. Existence and Approximation of Fixed Points of Enriched Contractions and Enriched $\varphi$-Contractions. Symmetry 2021, 13, 498. [CrossRef]

35. Berinde, V.; Păcurar, M. Fixed Points Theorems for Unsaturated and Saturated Classes of Contractive Mappings in Banach Spaces. Symmetry 2021, 13, 713. [CrossRef] 
36. Berinde, V.; Păcurar, M. Fixed point theorems for enriched Ciric-Reich-Rus contractions in Banach spaces and convex metric spaces. Carpathian J. Math. 2021, 37, 173-184. [CrossRef]

37. Berinde, V.; Ţicală, C. Enhancing Ant-Based Algorithms for Medical Image Edge Detection by Admissible Perturbations of Demicontractive Mappings. Symmetry 2021, 13, 885. [CrossRef]

38. Fukhar-ud-din, H.; Berinde, V. Iterative methods for the class of quasi-contractive type operators and comparison of their rate of convergence in convex metric spaces. Filomat 2016, 30, 223-230. [CrossRef]

39. Berinde, V. Convergence theorems for fixed point iterative methods defined as admissible perturbations of a nonlinear operator. Carpathian J. Math. 2013, 29, 9-18. [CrossRef]

40. Berinde, V.; Măruşter, Şt.; Rus, I.A. An abstract point of view on iterative approximation of fixed points of nonself operators. J. Nonlinear Convex Anal. 2014, 15, 851-865.

41. Berinde, V.; Petruşel, A.; Rus, I.A.; Şerban, M.A. The retraction-displacement condition in the theory of fixed point equation with a convergent iterative algorithm. In Mathematical Analysis, Approximation Theory and Their Applications; Springer: Cham, Switzerland, 2016; Volume 111, pp. 75-106

42. Mondal, P.; Garai, H.; Dey, L.K. On some enriched contractions in Banach spaces. arXiv 2020, arXiv:2006.11500. 